\title{
26408 - COMPARISON OF DEPTH OF ANESTHESIA BETWEEN PARACETAMOL AND REMIFENTANIL IN ENDOSCOPIC SINUS SURGERY BY BIS MONITORING
}

\section{Valiollah Hassani Professor of Anesthesiology, Farnad Imani, Mohamad Farhadi, Azin Mirsadraei, Iran University Of Medical Sciences, Tehran, TEHRAN, Iran}

INTRODUCTION:

Paracetamol is a non-opioid and non-NSAIDs analgesic with central function. This drug is similar to opioid and NSAIDs to produce analgesia, but different from those in their side effects. Analgesic effect of iv paracetamol is similar to opioids and NSAIDs, but has no their side effects. Remifentanil is an ultra short-acting opioid. BIS index is a complex EEG parameter. BIS values of 0 represent an isoelectric EEG, where values of 100 represent an awake patient. In our study, we assess the effect of these two drugs on depth of anesthesia using BIS monitoring.

\section{METHODS:}

This study was done on 100 patients in ASA-1, who were candidate for functional endoscopic sinus surgery (FESS). Diabetes, hypertension, and cardiopulmonary diseases were excluded. After ethical approval, patients were randomly divided in two groups ( $\mathrm{P}$ and $\mathrm{R}$ groups). Premedication included iv fentanyl $1 \mathrm{mcg} / \mathrm{kg}$ for both groups. Also, induction of anesthesia in both groups was propofol $2.5 \mathrm{mg} / \mathrm{kg}$, cisatracurium 0.15 $\mathrm{mg} / \mathrm{kg}$, and for maintenance, propofol $100 \mathrm{mcg} / \mathrm{kg} / \mathrm{min}$ plus $\mathrm{N} 2 \mathrm{O} \mathrm{50 \%}$ and $\mathrm{O} 250 \%$, but paracetamol 1 gr every $4 \mathrm{~h}$ in P group, and remifentanil $1 \mathrm{mcg} / \mathrm{kg} / \mathrm{min}$ in R group were administrated. Depth of anesthesia (BIS) were recorded before premedication (T1), before induction of anesthesia (T2), during laryngoscopy (T3) and intubation (T4), skin incision (T5), and during operation (T6). Furthermore, non-invasive blood pressure and heart rate was monitored. Data were evaluated by independent sample t-test and $\mathrm{P}<0.05$ was statistically considered significant.

\section{RESULTS:}

Demographic data was not significant difference between groups. Furthermore, There were not significantly differences in BIS between $\mathrm{P}$ and $\mathrm{R}$ groups at $\mathrm{T} 1(98.7 \pm 2.6$ vs

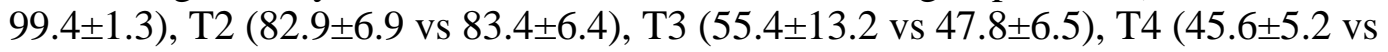
$46.3 \pm 5.3)$, T5 (46.7 \pm 7.6 vs $44.2 \pm 3.6)$, and T6 (46.4 \pm 9.8 vs $44.4 \pm 5.7)(\mathrm{P}>0.05)$. Thus, there were not differences between iv paracetamol and remifentanil on depth of anesthesia, which monitored by BIS, during endoscopic sinus surgery (FESS).

\section{DISCUSSION:}

These finding suggested that infusion of paracetamol, as an analgesics for maintenance of anesthesia, can be used instead of remifentanil during FESS.

Key words: BIS, paracetamol, remifentanil, FESS

\section{REFERENCE:}

Anaesth Analg 2005 Sep;32(5):241-55. 